\section{Knowledge of Pollinator Conservation and Associated Plant Recommendations in the Horticultural Retail Industry}

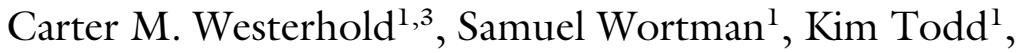 \\ and Douglas Golick ${ }^{2}$
}

ADDITIONAL INDEX WORDs. retail horticulture, employee education, pollinator plants, pollination, pollinator knowledge, plant sales

\begin{abstract}
Summary. Pollinating insects are integral to the health of all terrestrial ecosystems and agriculture worldwide. Urbanization can greatly reduce nutritional resources and habitat for pollinators. However, these losses can be mitigated through targeted landscape practices, such as planting nectar- and pollen-rich plants and managing pollinator habitat in urban areas, especially home landscapes. As homeowners attempt to conserve pollinators through horticultural practices, they often seek the advice and guidance of horticulture retail employees. The knowledge horticulture employees have about pollinators and the recommendations they provide to customers is largely unknown. A nationwide survey was developed and distributed with the objectives to 1 ) assess employee knowledge about pollinators and pollination biology, 2) discover what plant and management recommendations employees were giving customers pertaining to pollinator conservation, and 3) determine where to focus possible education and outreach, as well as which topics to focus educational programs on. Our findings suggest, among our respondents, that overall knowledge was adequate, with a mean score $( \pm S D)$ being $8.37( \pm 3.23)$ of a possible range of $0-14$ points. Uncertified and part-time employees were identified as having significantly lower scores. The subject of plant selection was found to have the largest gap in knowledge, with a mean score of $1.82( \pm 0.62)$ of a possible three points. We identified several opportunities for educational outreach, aimed at improving employee and customer knowledge on this important subject.
\end{abstract}

$\mathrm{M}$ uch public attention has focused on the decline of pollinating insects, in part due to european honeybee (Apis mellifera) colony collapse disorder. Since 2006, beekeepers have been reporting an average annual winter loss of $30 \%$ of their hives (Kulhanek et al., 2017). The decline of pollinating insects is likely a result of multiple factors including changes in climate, parasites, disease, pesticides, and interactions among these factors (Goulson et al., 2015). However, the greatest contributing factor is thought to be habitat and forage loss (Goulson et al., 2015; Kerr et al., 2015; Vanbergen and Initiative, 2013), which is a result

This paper was a portion of a thesis submitted by Carter M. Westerhold in fulfillment of a Master of Science degree.

${ }^{1}$ Department of Agronomy and Horticulture, University of Nebraska-Lincoln, 279 Plant Sciences Hall, Lincoln, NE 68583

${ }^{2}$ Department of Entomology, University of NebraskaLincoln, 1700 East Campus Mall, Lincoln, NE 68503

${ }^{3}$ Corresponding author. E-mail: westerhold.carter@ gmail.com.

https://doi.org/10.21273/HORTTECH03973-18 of increased land use intensification through urbanization.

Numerous studies have found that when appropriate floral resources are present, urban areas have the capacity to support healthy pollinator populations (Baldock et al., 2015; Davis et al., 2017; Geslin et al., 2015; Lowenstein et al., 2015; Persson et al., 2015; Potter and LeBuhn, 2015; Sirohi et al., 2015; Threlfall et al., 2015; Wray and Elle, 2015). Because of the relatively small functional requirements, habitat range, short life cycle, and nesting behavior of pollinators, urban areas can be suitable places devoted to their conservation (Hall et al., 2017). Despite numerous factors that would make urban areas unsuitable for pollinators, such as lack of exposed ground because of concrete, the presence of diverse floral resources has been found to overcome negative effects of many of these factors (Hülsmann et al., 2015).

Although most of this land is private, Helfand et al. (2006) suggest that many homeowners are willing to have their landscapes take on an ecological role by adopting practices such as planting native plants. Pollinator conservation in the home landscape can be a challenge for homeowners because of the complexities of knowing which plants are beneficial to pollinators, how to design landscape features beneficial to pollinators, how to manage pollinator habitat, and how to reduce chemical inputs. Expecting homeowners to possess the knowledge and skills necessary to design and manage pollinator habitat may be unrealistic. Indeed, a 2017 survey of college science majors, soon to be homeowners, found deficiencies in knowledge of pollinators and conservation practices (Golick et al., 2017). A combined lack of knowledge of pollinators and various landscaping topics to sustain pollinator habitat is a barrier to implementing sound pollinator conservation practices.

Homeowners use many convenient resources, such as websites, books, and workshops to educate themselves on various landscape topics and pollinator conservation. Although many of these resources give helpful recommendations, some, such as online plant lists, may have little empirical evidence to support their value to pollinators (Garbuzov and Ratnieks, 2014). A common source of landscaping information for homeowners is the point of sale of their plant materials (Meyer and Foord, 2008). This leaves horticulture retail stores, garden centers, and their employees at the forefront of public education about pollinator conservation and landscaping.

Public interest in pollinator conservation has increased markedly in the past decade (Wilson et al., 2017). The number of homeowners seeking pollinator conservation advice from horticulture retail should rise as well. Knowledgeability of horticulture retail staff in plant selection is an important quality for a garden center to have (Barton et al., 1998; Safley and Wohlgenant, 1995). It is unknown how knowledgeable these professionals are in selecting plants for pollinators and other related pollinator conservation practices. Because of the importance of pollinators and the need for their conservation, it is important to ensure that the information homeowners are given from retailers is accurate. To measure horticulture 
retail knowledge of pollinators and their conservation, we conducted a nationwide survey of horticulture retail employees. The objectives of this survey were to 1 ) assess pollinator and pollination biology knowledge of horticulture retail employees that interact with customers, 2) discover what plant and management recommendations employees were giving customers pertaining to pollinator conservation, and 3 ) determine where to focus possible education and outreach, as well as which topics to focus educational programs on.

\section{Materials and methods}

The survey was developed with questions to determine plant species being recommended by horticulture retail employees to customers to attract pollinators, what landscape practices were being recommended to customers wanting to conserve pollinators, and how knowledgeable employees were about pollinators, pollinator biology, plant selection, and landscaping practices recommendations for pollinators. We developed an online survey and script of followup interview questions and had it reviewed by the Institutional Review Board to assure the safety and privacy of the respondents during the study. After approval, the survey was published and distributed online using Qualtrics software (Experience Management, Provo, UT). The survey contained 22 questions, a combination of open-ended, close-ended, and rank-order questions (see Supplemental Table 1). Filtering and distraction responses were used to eliminate nontarget respondents and respondents who possibly falsified survey responses, respectively. For example, respondents who said they did not work directly with customers were removed from the survey entirely. The final question asked respondents to volunteer for a short, recorded phone interview.

An e-mail list of possible survey participants was purchased from Exact Data Inc. (Chicago, IL). Possible survey participants were identified as part of the survey population using a four-digit Standard Industrial Classification (SIC) code associated with their place of employment. These SIC codes were tied to industries related to horticulture retail and other horticulture-related industries.
In addition, the survey was posted on social media and shared through newsletters or by e-mail by the landscape associations of California, Texas, Iowa, New York, Minnesota, Oregon, and Nebraska; the Association of Professional Landscape Designers; American Horticulturist Association; Florida Association of Native Nurseries; the Nebraska Statewide Arboretum; Nebraska Turf Association; and Western Nursery and Landscape Association. In total, the survey was available to an estimated $7500+$ individuals. To increase participation, two reminder emails were sent and participants were given a chance to win a $\$ 25$ gift card. The survey was available from $28 \mathrm{Feb}$. to 24 Apr. 2017.

Responses were scored by coauthors D. Golick and C. Westerhold using the pollination framework metrics described in Golick et al. (2017), and later reconciled into a single final score for each response (Table 1). Respondents with higher scores were said to be more knowledgeable about pollinator biology and gave "better" or more correct suggestions on landscaping practices. Questions 14, 15, 16 , and 17 were all scored. All scores were then totaled to give each respondent a total knowledge score. The highest possible total knowledge score was 14 , and the lowest possible score was 0 .

Using R Statistical software (version 3.4.1; R Studio, Boston, MA), total knowledge scores were compared among demographic responses; depending on the number of possible responses to each demographic question, a $t$ test (two responses) $(\alpha=$ 0.05 ) or analysis of variance (three or more responses) $(\alpha=0.05)$ was used to summarize and interpret responses. Demographic variables, including time spent with customers, years of experience, job title, age, gender, education, certification, store type, store operating season, and location were all compared. In the rankorder question, the mean score of each plant attribute was calculated to determine what respondents found most to least important. A MannWhitney test with 95\% confidence was performed to determine any differences in ranking among demographic groups using SPSS statistical software (version 25; IBM, Armonk, NY). Phone interviews were used to gather more detailed information on respondents' survey responses. The interview discussions were semistructured, guided by questions with additional prompts for elaboration of answers where appropriate. Interviews were recorded, transcribed, summarized, and interpreted by coauthors D. Golick and C. Westerhold to determine if any themes derived from commonalities existed among interviewee responses.

\section{Results}

SuRVEY RESPONSE. The survey had 224 respondents. Of those, 114 completed all questions and properly answered the distractor question responses. Descriptive statistics were used to conceptualize scores earned by respondents on each scored question as well as the total scores (Table 2).

Demographics. Of the 114 respondents, 50 were female and 64 were male. The age groups of 55-64 years old were the most prevalent (36\%), followed by $45-54$ years old $(21 \%)$ and $35-44$ years old (17\%). Most respondents $(73 \%)$ were college-educated, stating they had a degree past a high school diploma. Respondents' job titles were primarily business owners $(26 \%)$, landscape designers $(23 \%)$, and sales associates $(20 \%)$. More than half of the respondents $(59 \%)$ worked at local horticultural retail businesses, whereas "other" was the next most common response $(30 \%)$. Among other descriptions, "other" included groundskeepers, designers, and governmental/ nonprofit employees. These various types of workers were mostly certified in their field, with $61 \%$ reporting some sort of horticultural certification in their state. Only $27 \%$ of respondents worked at businesses that sold plants year-round.

Pollinator KNOWledge. In the first pollinator knowledge question, "which of the insect choices below are considered important plant pollinators?" the highest possible knowledge score was five. Respondents scored high, with the mean score $( \pm S D)$ among respondents being $3.63( \pm 1.21)$. For the question, "how do insects benefit from pollinating plants?" open response answers were provided by participants. Out of a possible knowledge score of three, the mean knowledge 


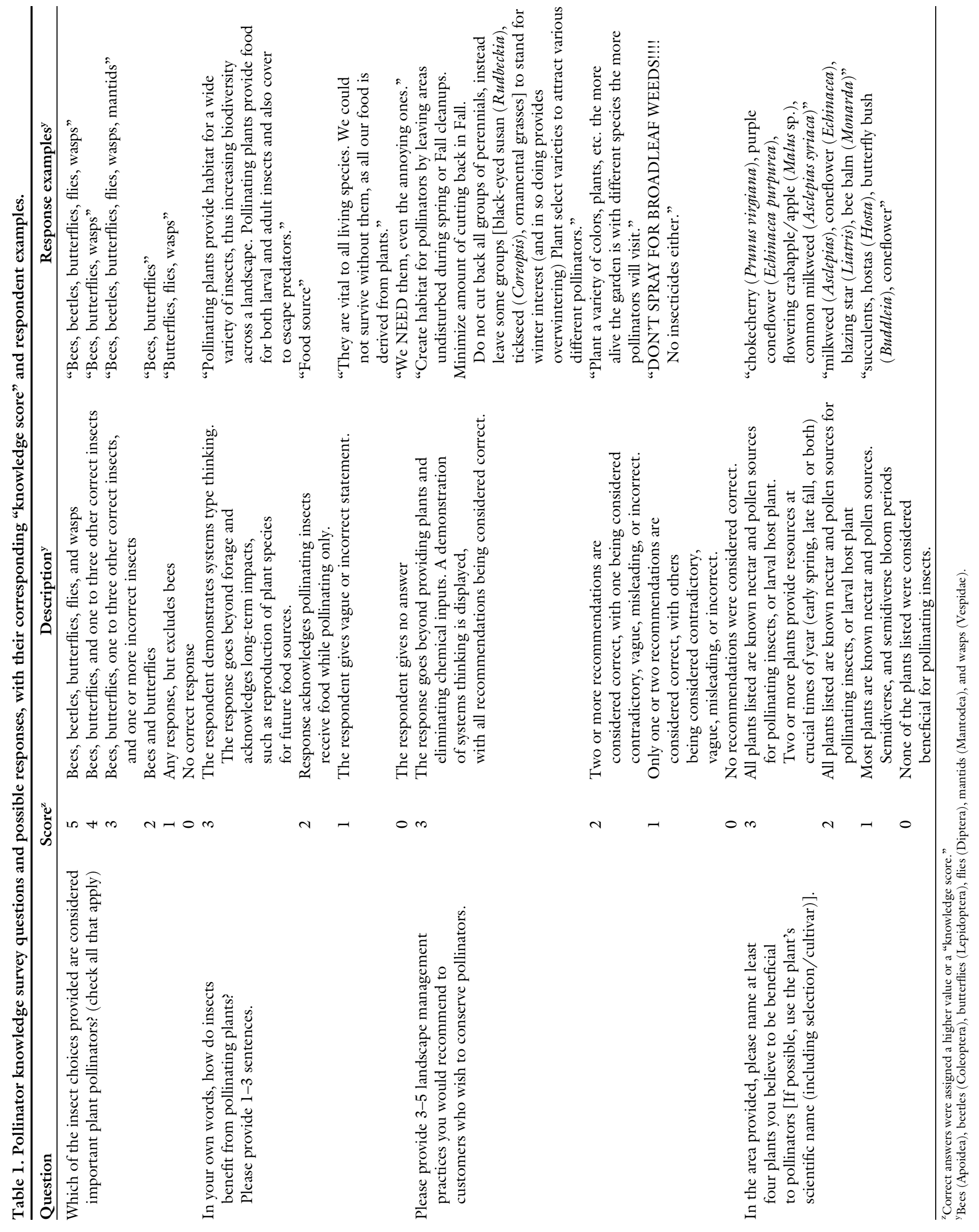

Hortlechnology · August 2018 28(4) 


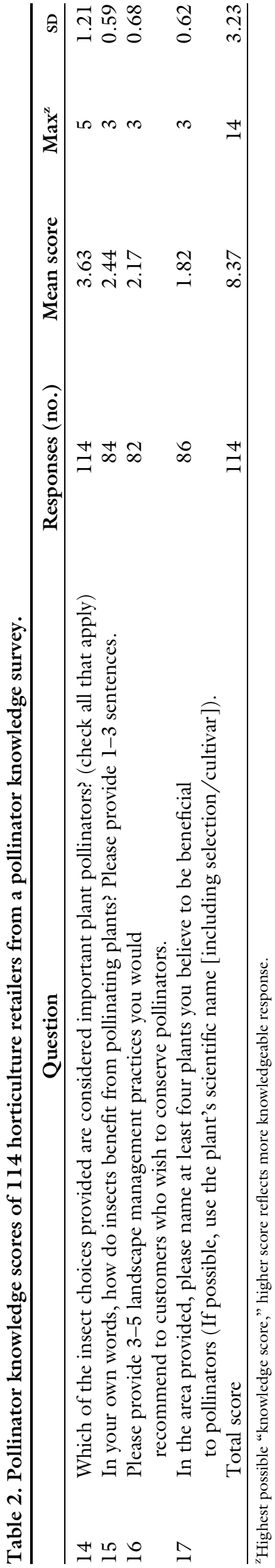

score was $2.44( \pm 0.59)$. The benefits of food represented $35 \%$ of the responses; of these, nectar was specifically mentioned as a food source (15\%) of the time, whereas pollen was specifically mentioned much less often (5\%). Benefits identified, apart from "food," were plant reproduction to create more forage resources (plants) $(15 \%)$, insect reproduction $(11 \%)$, and habitat (11\%).

Plant and management ReCommendations. A total of 203 different landscape recommendations were provided after respondents were prompted to "Please provide three to five landscape management practices you would recommend to customers who wish to conserve pollinators." Providing plants for pollinators was the most common recommendation $(22 \%)$, followed by careful use of chemicals $(18 \%)$, create/leave habitat $(14 \%)$, no chemicals ( $12 \%)$, reducing outside inputs $(12 \%)$, providing successional blooming of plants $(10 \%)$, and using native plants (10\%). Remaining recommendations (less than $1 \%$ each) were grouping plants together, teaching others about pollinators, and learning more about pollinators.

When asked to "name at least four plants you believe to be beneficial to pollinators," respondents gave a wide range of responses. These responses were grouped together according to plant genus to find commonalities among respondents. The most popular plant genera mentioned were milkweed [Asclepias (14\%)], coneflower [Echinacea (8\%)], aster [Aster (5\%)], and butterfly bush [Buddleia (5\%)]. Other popular responses ( $>1 \%$ each) included bee balm (Monarda), blazing star (Liatris), salvia (Salvia), sedum (Sedum), rue (Ruta), goldenrod (Solidago), trillium (Trillium), catmint (Nepeta), black-eyed susan (Rudbeckia), yarrow (Achillea), false indigo (Baptisia), boneset (Eupatorium), russian sage (Perovskia), sunflower (Helianthus), apple (Malus), beardtongue (Penstemon), mountain mint (Pycnanthemum), and cherry (Prunus). The plant forms listed were forbs $(63 \%)$, shrubs $(22 \%)$, trees $(10 \%)$, and grasses $(4 \%)$.

Following plant recommendations, respondents were also asked, "which of the choices below best describe why you chose the plants you did in the previous question?" Most respondents (91\%) cited that they knew which plants were good for pollinators based on personal observation. Additional sources of information on beneficial pollinator plants included academic or industry research $(52 \%)$; reading an article about the plant in a trade magazine, online, or elsewhere (40\%); and hearing from others that the plant was good for pollinators $(31 \%)$. In the next question, respondents were asked, "are you more likely to recommend a native plant than non-native plant, where these plants otherwise have all of the same growing requirements and attraction to pollinators?" More than half of the respondents $(62 \%)$ chose "yes," which suggests that many respondents may consider native plants more beneficial for pollinators in this context.

RANK ORDER OF IMPORTANT PLANT ATTRIBUTES FOR POLLINATORS. In a ranked-order-type question, respondents were asked, "when recommending plants to a customer who is interested in attracting pollinators, how would you rate the importance of the following plant attributes? 1) being most important and 10) being least important" (Table 3). Most attribute rank orders were not different among demographic groups; however, respondents with certifications ranked "attractiveness to pollinators" higher (first) than those without certification [ninth $(P=0.041)]$.

Pollinator KNOWLEDGE AMONG DEMOGRAPHIC GROUPS. Knowledge scores varied significantly within three demographic variables: 1) gender, 2) certification, and 3 ) store operating season. Female respondents had a higher mean total knowledge score (9.06) compared with male respondents $(7.83)(P=0.037)$. Respondents with any type of professional certification had a higher mean total knowledge score (9.04) than those without certification (7.33) $(P=$ $0.005)$. Respondents who reported to work at a store that was open all year had a higher average score (9.94) than those who worked at stores for only part of the year (8.20) or just for a season $(7.60)(P=0.003)$. However, knowledge scores were not influenced by time spent with customers, years of experience, job title, age, education, store type, and location. 
Table 3. Perceived importance of plant attributes to horticulture employees in regard to attracting pollinators, ranked from most important (1) to least important (10).

\begin{tabular}{lll}
\hline Rank of importance & \multicolumn{1}{c}{ Plant attribute } & \multicolumn{1}{c}{ Mean rank $^{\mathbf{z}}$} \\
\hline 1 & Attractiveness to pollinators & 3.570175 \\
2 & Bloom period & 3.929825 \\
3 & Origin (native or introduced) & 4.149123 \\
4 & Sun and water requirements. & 4.517544 \\
5 & Bloom color & 5.017544 \\
6 & Life span (perennial or annual) & 5.77193 \\
7 & Size & 6.070175 \\
8 & Specific selection/cultivar & 6.964912 \\
9 & Presence of plant protective pesticides & 7.5 \\
10 & Price & 7.508772 \\
\hline
\end{tabular}

${ }^{\mathrm{z}} \mathrm{A}$ low mean rank corresponds to a higher perceived importance and a high mean rank corresponds to a lower perceived importance.

CUSTOMER ADVICE AND QUESTIONS. To understand what kind of questions customers were asking at garden centers, respondents were asked to "list up to three common questions customers ask you about pollinators, pollinator plants, or both." The questions that customers asked employees most were as follows: "what plants are best for pollinators?" (21\%), questions about general plant attributes/ requirements $(18 \%)$, "how I attract butterflies, specifically?” (14\%), “will this chemical hurt the bees/butterflies?" $(7 \%)$, "will this attract bees? I don't want to get stung by bees." (6\%), "what landscape practices will help pollinators?" (5\%), "does this plant have neonicotinoids?" (5\%), and "do native plants attract more pollinators?" (5\%).

InTERVIEWs. Seven respondents volunteered for phone interviews. These volunteers varied in their backgrounds and their occupations, and included educators, groundskeepers, sales associates, and landscape designers. However, many of the responses they gave were very similar. The first question asked during the interview was, "When you completed the survey, you listed four plants as choices for good pollinator plants. Can you tell me a little about why you chose these plants?" Consistent with the initial survey, personal observation was the most common response. For example, a volunteer said, "Well, partially it's based on observations, I've been here for ages...for my whole life I've watched and enjoyed (insects) as a kid. So, most of my information is based on personal experiences."

In another question, "can you tell me how you have learned what you know about pollinators and conservation?" volunteers almost unanimously said that it was based on their own personal experiences of observing pollinators in the garden and landscape. However, one volunteer gave a specific information source, saying, "The Xerces Society, also the local state university. (The university) has some really nice little booklets about pollinators in our area they give out for free."

In response to, "what do you believe are the biggest challenges in planting/designing landscapes for pollinators?" every volunteer mentioned lack of knowledge on the part of their customers. For example, one volunteer said, "So I think that it has to be about education and you have to educate them (the public) in a way that makes them want more. You can't beat them with it."

Every volunteer said they shared their knowledge of pollinators with coworkers and others outside of the work environment. One volunteer said, "I do (share knowledge) on a regular basis. None of my information is exclusively private. We live in a very free world, people can Google anything they want. So, you may as well share your information and that makes you a, I don't want to say an expert, but a knowledgeable individual in the field. People come back to me to design for them and find information. I consider that very valuable. I share on social media, I share on my website, and I tweet a lot, so all those sources are frequently used."

When asked, "in your experiences working with customers, what are their major concerns when choosing plants in their landscapes?" customer concerns came to the forefront of the discussion. For example, one interviewee said, “(customer's concerns are) that the plants are going to look good; that they are going to last, meaning they are not going to die; that they are going to appeal to the clients, and their friends, and family; and they're going to be low maintenance, low maintenance for you know trimming, deadheading, and maintenance."

When questioned, "do you have a gardening philosophy?" all the volunteers said yes but did not have a prepared answer. One respondent did have a prepared gardening philosophy stating to "garden for life," life pertaining to pollinators and other beneficial insects. In the following question, "do you think the business you work for cares about pollinators?" all volunteers replied "yes," but were unable to provide specific examples of how their respected businesses express a concern for pollinators. In our final question, "are the plants your business sells labeled as being beneficial for pollinators? (i.e., food, habitat, etc.)," only one volunteer said their business labeled their plants for pollinators, describing that the plant labels for pollinator plants had "a small butterfly on it."

\section{Discussion}

Survey results suggest that most employees have some knowledge about pollinators, pollinator biology, plant selection, and landscaping practices recommendations for pollinators. Additional strengths among respondents were in knowing what insect groups were known pollinators, understanding the mutual benefits of pollination, and what landscape practices were best for conserving pollinators.

Knowledge of beneficial plants for pollinators was the weakest subject, having the lowest mean knowledge score (mean $=1.82$ ). Plant recommendations were dominated by summer blooming forbs, despite early spring and late fall blooming plants being crucial for pollinator health (Mader et al., 2011). Trees and shrubs, although mentioned less often by respondents, are some of the earliest and latest blooming forage plants for bees and are forage plants for generalist and solitary bees (MacIvor et al., 2014; Mader et al., 
2011). This result highlights the need to educate retailers about the importance of early and late blooming plants as well as the importance of trees and shrubs in pollinator conservation.

Respondents without certification had a significantly lower total knowledge score $($ mean $=7.33$ ) on the scored survey questions than their counterparts with certifications $($ mean $=9.04)(P=0.005)$. This was also true for respondents who worked at year-round businesses (mean = 9.94) as compared with seasonal $($ mean $=7.60)(P=0.003)$ and parttime business $($ mean $=8.20)(P=$ $0.009)$. If pollinator conservation is a topic of importance to a retail business, results suggest requiring professional horticultural certification of some kind may be of value to employers. In cases where certification is not feasible, our suggestion is to encourage more knowledgeable or certified employees to reach out to their peers and share their knowledge.

For businesses lacking certified or knowledgeable employees, we recommend labeling pollinator food plants, as customers may purchase more pollinator-friendly plants when correctly labeled as "pollinator friendly" (Campbell et al., 2017). Also, businesses could distribute information on pollinator conservation in the form of pamphlets/booklets, focusing on plant selection and landscape management. Garbuzov and Ratnieks (2014) found that many online plant lists were based on personal experiences rather than on empirical data. There is a good chance this is how respondents chose their plants as well, as our interviewees stated personal experiences of observing pollinators as a source of knowledge of pollinator plants. Despite this, many high-quality pollinator conservation publications exist online from reliable sources (e.g., Xerces Society, U.S. Forest Service, and U.S. Department of Agriculture). It is uncertain if homeowners are aware of these reputable sources. Retailers could keep regionally specific lists based on these reputable sources on hand to help guide customers and uncertain employees in plant selection, as plant selection was the lowest scoring subject for respondents.

In addition to improving knowledge on plant selection through pamphlets/booklets, we recommend educational materials to also focus on landscape management practices, and a list of significant pollinators. Although many employees understood which major insect groups were responsible for pollination, there is a lack of awareness on the significance of bees as a group. Most responses focused on butterflies and conservation. Respondents showed a higher interest in conserving butterflies than bees, despite bees being significantly more efficient pollinators (Mader et al., 2011). Public knowledge of bees seems to be low overall; a recent survey found that only $14 \%$ of respondents were able to guess the number of bee species in the United States to the nearest thousand, despite nearly all respondents $(99 \%)$ stating that bees are critically important (Wilson et al., 2017).

Horticulture retail staff rated the importance of the presence of plant protective chemicals (pesticides) ninth in importance of plant attributes. This is surprising, given that pesticides are a known risk to pollinator health. A recent survey found that nearly $70 \%$ of garden center plants sold to the public were found to contain neonicotinoid pesticides (Lentola et al., 2017). Neonicotinoid pesticides have been implicated by studies as one of the causes of pollinator declines (Goulson, 2013; Rundlöf et al., 2015; Van der Sluijs et al., 2013; Whitehorn et al., 2012). Raising employee awareness about the presence of pesticides could be helpful for increasing customer awareness about the possible risks of exposing pollinators to pesticides.

\section{Conclusions}

This survey provides insight about what horticultural retailers know about pollinators and what they are telling their customers. Horticulture retail employees are best-positioned to inform homeowners on pollinator conservation practices; therefore, it is critically important that horticultural retail sales employees working with customers are either knowledgeable of evidence-based pollinator conservation practices or have access to educational materials to distribute to customers. Horticultural professionals are important stakeholders in pollinator conservation. Our hope is that the results of this study can be used to guide educational outreach to better educate and equip horticultural retail sales employees with effective pollinator conservation information and strategies, ultimately improving homeowner pollinator conservation practices.

\section{Limitations}

One of the limitations of this research is the relatively low sample size to survey distribution. Low response rates in surveys are not uncommon. We did our best to reach horticulture retail sales employees across the United States by using multiple recruitment methods. The low response may be due to the nature of trying to reach people in a largely seasonal industry. In addition, our response rate may also have been harmed by the length of the survey and the fact that many questions required reflection and recall on the part of respondents to answer them. We believe that this is supported by the 110 respondents who started the survey but did not complete it. Also, the fact that $73 \%$ of respondents had a degree past a high school diploma (the national U.S. post-high school degree attainment is $46 \%$ ) (McFarland et al., 2017) responses to the survey's knowledge questions may be skewed. Another limitation of this research is that we did not ask respondents to clarify what types of certifications they held. When designing this study, we did not anticipate a need to classify individual certifications. This information would have been helpful to better characterize pollination conservation knowledge and ties to specific training. Future studies looking at knowledge of horticulture sales force should ask respondents to list the type of certifications that they have.

\section{Literature cited}

Baldock, K.C.R., M.A. Goddard, D.M. Hicks, W.E. Kunin, N. Mitschunas, L.M. Osgathorpe, S.G. Potts, K.M. Robertson, A.V. Scott, G.N. Stone, I.P. Vaughan, and J. Memmott. 2015. Where is the UK's pollinator biodiversity? The importance of urban areas for flower-visiting insects. Proc. Biol. Sci. 282:1803.

Barton, S., J. Brooker, C. Hall, and S. Turner. 1998. Review of customer preference research in the nursery and 
landscape industry. J. Environ. Hort. 16:118-124.

Campbell, B., H. Khachatryan, and A. Rihn. 2017. Pollinator-friendly plants: Reasons for and barriers to purchase. HortTechnology 27:831-839.

Davis, A.Y., E.V. Lonsdorf, C.R. Shierk, K.C. Matteson, J.R. Taylor, S.T. Lovell, and E.S. Minor. 2017. Enhancing pollination supply in an urban ecosystem through landscape modifications. Landsc. Urban Plan. 162:157-166.

Garbuzov, M. and F.L.W. Ratnieks. 2014. Listmania: The strengths and weaknesses of lists of garden plants to help pollinators. Bioscience 64:1019-1026.

Geslin, B., V. Le Féon, M. Kuhlmann, B.E. Vaissière, and I. Dajoz. 2015. The bee fauna of large parks in downtown Paris, France. Ann. Soc. Entomol. Fr. (N.S.) 51:487-493.

Golick, D., J. Dauer, L. Lynch, and E. Ingram. 2017. A framework for pollination systems thinking and conservation. Environ. Educ. Res. 12:1-16.

Goulson, D. 2013. An overview of the environmental risks posed by neonicotinoid insecticides. J. Appl. Ecol. 50:977-987.

Goulson, D., E. Nicholls, C. Botías, and E.L. Rotheray. 2015. Bee declines driven by combined stress from parasites, pesticides, and lack of flowers. Science 347: 1255957.

Hall, D.M., G.R. Camilo, R.K. Tonietto, J. Ollerton, K. Ahrné, M. Arduser, J.S. Ascher, K.C.R. Baldock, R. Fowler, G. Frankie, D. Goulson, B. Gunnarsson, M.E. Hanley, J.I. Jackson, G. Langellotto, D. Lowenstein, E.S. Minor, S.M. Philpott, S.G. Potts, M.H. Sirohi, E.M. Spevak, G.N. Stone, and C.G. Threlfall. 2017. The city as a refuge for insect pollinators. Conserv. Biol. 31:24-29.

Helfand, G.E., J. Sik Park, J.I. Nassauer, and S. Kosek. 2006. The economics of native plants in residential landscape designs. Landsc. Urban Plan. 78:229-240.
Hülsmann, M., H. von Wehrden, A-M. Klein, and S.D. Leonhardt. 2015. Plant diversity and composition compensate for negative effects of urbanization on foraging bumble bees. Apidologie (Celle) 46:760-770.

Kerr, J.T., A. Pindar, P. Galpern, L. Packer, S.G. Potts, S.M. Roberts, P. Rasmont, O. Schweiger, S.R. Colla, and L.L. Richardson. 2015. Climate change impacts on bumblebees converge across continents. Science 349:177-180.

Kulhanek, K., N. Steinhauer, K. Rennich, D.M. Caron, R.R. Sagili, J.S. Pettis, J.D. Ellis, M.E. Wilson, J.T. Wilkes, D.R Tarpy, R. Rose, K. Lee, J. Rangel, and D. VanEngelsdorp. 2017. A national survey of managed honey bee 2015-2016 annual colony losses in the USA. J. Apic. Res. 56:328-340.

Lentola, A., A. David, A. Abdul-Sada, A. Tapparo, D. Goulson, and E. Hill. 2017. Ornamental plants on sale to the public are a significant source of pesticide residues with implications for the health of pollinating insects. Environ. Pollut. 228:297-304.

Lowenstein, D.M., K.C. Matteson, and E.S. Minor. 2015. Diversity of wild bees supports pollination services in an urbanized landscape. Oecologia 179:811-821.

MacIvor, J., J. Cabral, and L. Packer. 2014. Pollen specialization by solitary bees in an urban landscape. Urban Ecosyst. 17:139-147.

Mader, E., M. Shepherd, M. Vaughan, S.H. Black, and G. LeBuhn. 2011 . Attracting native pollinators: Protecting North America's bees and butterflies. Storey Publ., North Adams, MA.

McFarland, J., B. Hussar, C. de Brey, T. Snyder, X. Wang, S. Wilkinson-Flicker, S. Gebrekristos, J. Zhang, A. Rathbun, A. Barmer, and F. Bullock Mann. 2017. The condition of education 2017. Natl. Ctr. Educ. Stat. NCES 2017-144.

Meyer, M.H. and K. Foord. 2008. Consumer preferences and perceptions of gardening information. HortTechnology 18:162-167.

Persson, A.S., M. Rundlöf, Y. Clough, and H.G. Smith. 2015. Bumble bees show trait-dependent vulnerability to landscape simplification. Biodivers. Conserv. 24:3469-3489.

Potter, A. and G. LeBuhn. 2015. Pollination service to urban agriculture in San Francisco, CA. Urban Ecosyst. 18:885893.

Rundlöf, M., G.K. Andersson, R. Bommarco, I. Fries, V. Hederström, L. Herbertsson, O. Jonsson, B.K. Klatt, T.R. Pedersen, and J. Yourstone. 2015. Seed coating with a neonicotinoid insecticide negatively affects wild bees. $\mathrm{Na}$ ture 521:77-80.

Safley, C.D. and M.K. Wohlgenant. 1995. Factors influencing consumers' selection of garden centers. J. Agribusiness 13:3350

Sirohi, M.H., J. Jackson, M. Edwards, and J. Ollerton. 2015. Diversity and abundance of solitary and primitively eusocial bees in an urban centre: A case study from Northampton (England). J. Insect Conserv. 19:487-500.

Threlfall, C.G., K. Walker, N.S.G. Williams, A.K. Hahs, L. Mata, N. Stork, and S.J. Livesley. 2015. The conservation value of urban green space habitats for Australian native bee communities. Biol. Conserv. 187:240-248.

Vanbergen, A.J. and T.I.P. Initiative. 2013. Threats to an ecosystem service: Pressures on pollinators. Front. Ecol. Environ. 11:251-259.

Van der Sluijs, J.P., N. Simon-Delso, D. Goulson, L. Maxim, J-M. Bonmatin, and L.P. Belzunces. 2013. Neonicotinoids, bee disorders and the sustainability of pollinator services. Curr. Opin. Environ. Sustain. 5:293-305.

Whitehorn, P.R., S. O'Connor, F.L. Wackers, and D. Goulson. 2012. Neonicotinoid pesticide reduces bumble bee colony growth and queen production. Science 336:351-352.

Wilson, J.S., M.L. Forister, and O.M. Carril. 2017. Interest exceeds understanding in public support of bee conservation. Front. Ecol. Environ. 15:460-466.

Wray, J.C. and E. Elle. 2015. Flowering phenology and nesting resources influence pollinator community composition in a fragmented ecosystem. Landsc. Ecol. 30:261-272. 


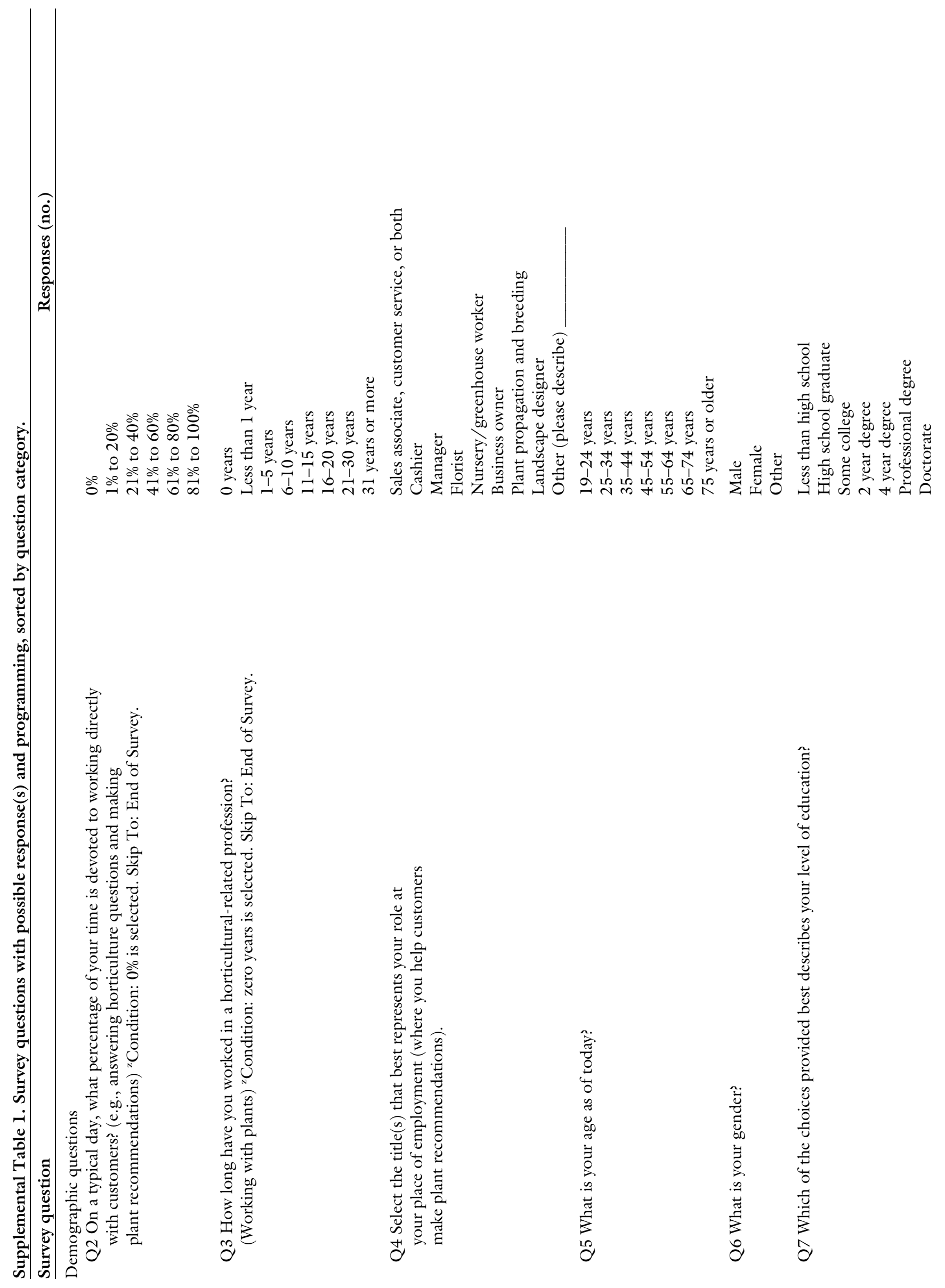

Hortlechnology · August 2018 28(4) 


\section{Extension Education Methods}
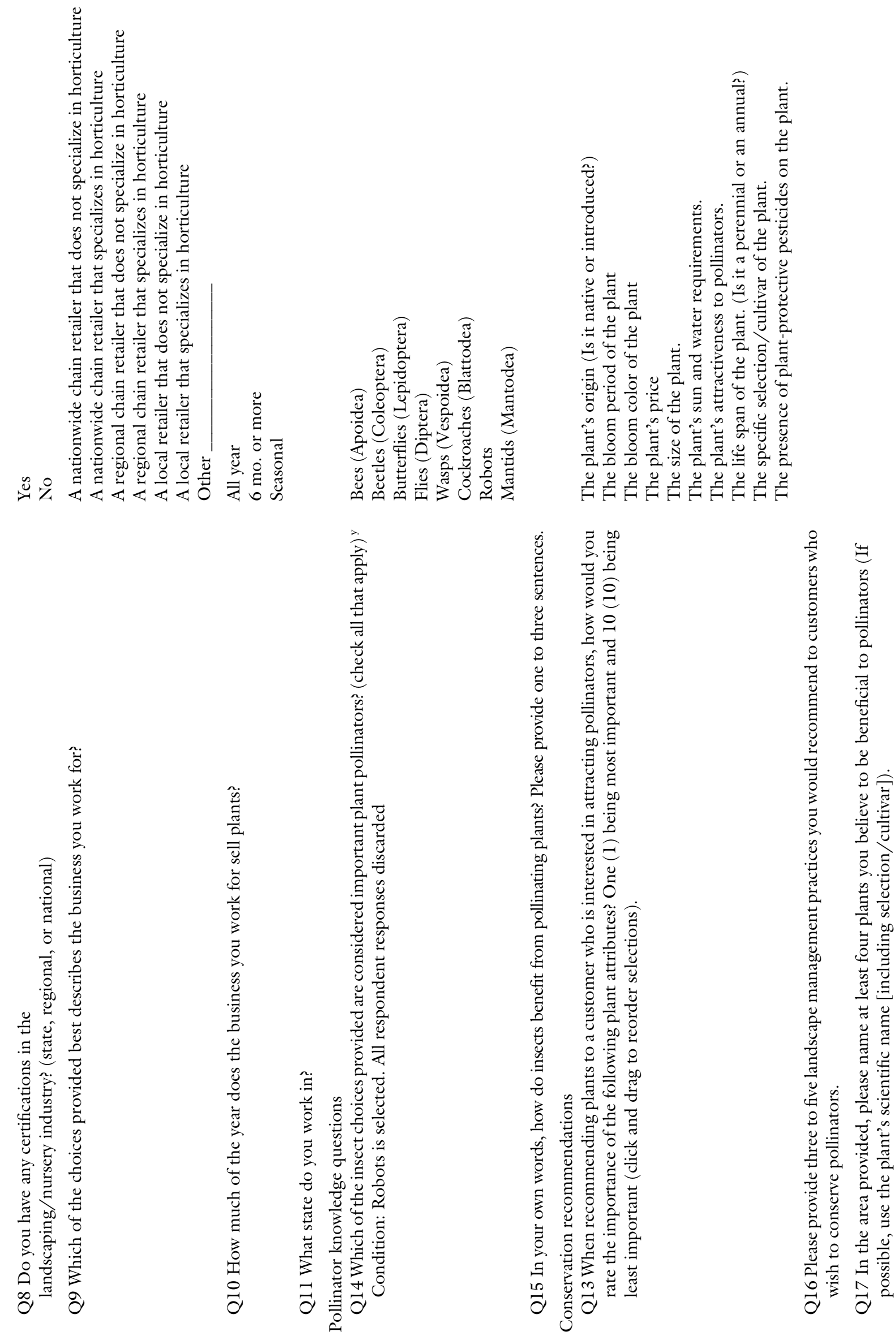


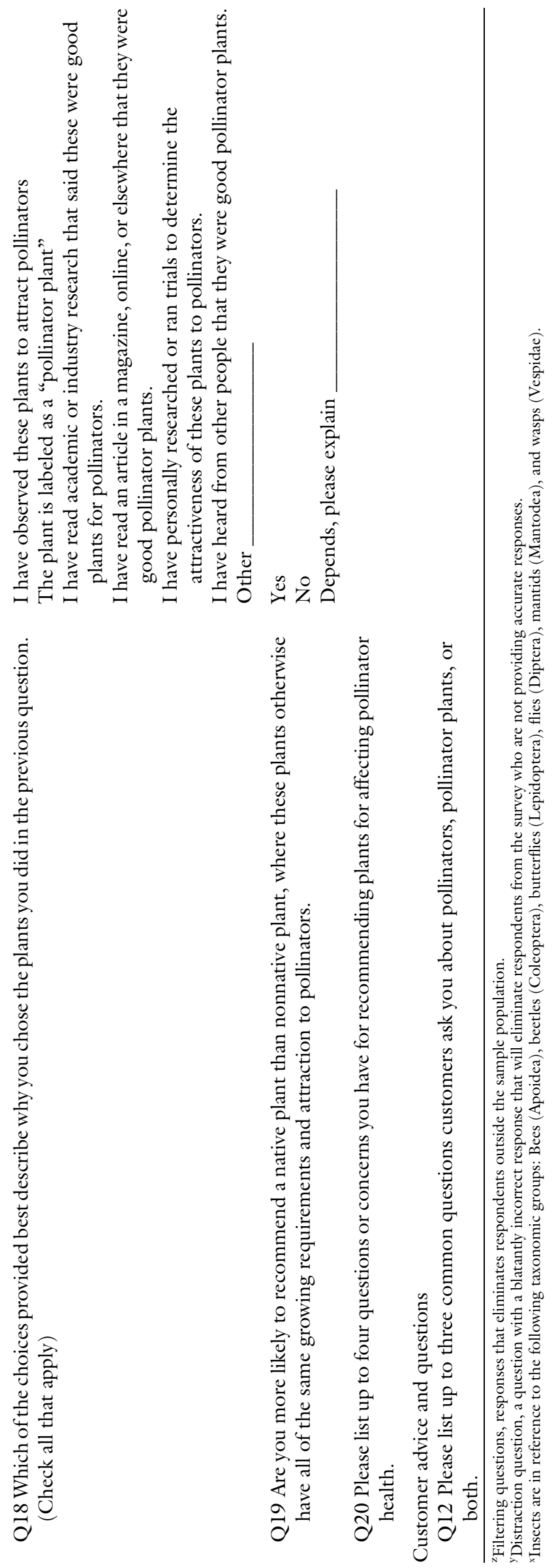

Hortlechnology · August 2018 28(4) 